\title{
A review of Multi Sensor Data Fusion for Signal Processing
}

\author{
Mahesh S Kumbhar \\ Research Scholar ,Shivaji University Kolhapur, India \\ Dr R H Chile \\ Professor, Electrical Engineering Department SGGSIET Nanded , India
}

\begin{abstract}
Nowadays sensors have become part and parcel of every technological development around the globe. The handling of data by sensors and its fusion is a very common scenario in networks having more number of nodes. Thus there is a need to highlight the different scenarios and techniques used for multi sensor data fusion. The paper illustrates the different techniques adapted by various researchers for signal processing and its allied activities.
\end{abstract}

Index Terms: Extended Kalman Filter- (EKF) and Adaptive Fuzzy Logic System (AFLS)

\section{INTRODUCTION}

In the recent years the interest has been grown in the synergistic use of multiple sensors to improve the capability of intelligent machines and systems. For such systems to use multiple sensors effectively, some techniques are required for integrating the information provided by these sensors into the operation of the systems, while in the many multisensor systems the information from each sensor serves as separate input to the system. The actual combination (fusion) of information is carried out prior to its use in the system. Multisensor fusion and integration refers to the synergistic combination of the sensors data from multiple sensors to provide more reliable and accurate information.

The main advantage of multisensor fusion and integration are redundancy complementary, timeliness and cost of information. The integration or fusion of redundant information can reduce overall uncertainty and this serve to increase the accuracy with which the features are perceived by the system. Multiple sensors providing redundant data can also serve to increase reliability in the case of sensor errors or failure. Complementary information from the multiple sensors allows in the environment to be perceived that are impossible to perceive using just the information from each individual sensor operating separately. More timely information may be provided by the multiple sensors due to either the actual speed of operation of each sensor or parallelism gyration that may be possible as a part of fusion processes.

Integration of sensory information provided by multiple sensors becomes more important in many applications. An optimal and computationally efficient algorithm for dynamic multisensor data integration was given in this burden of estimation was distributed among $\mathrm{N}$ sensor. In some algorithm where each sensor is considered in its local coordinate systems and communication networks among the sensors are allowed to have uncertainties with known statistics. Adaptive algorithm can be employed in uncertain sensed environment using imperfect sensors assuming little prior information about the sensed environment and the sensor. Here weights are adjusted for the best fusion of inaccurate data provided by the multiple sensors.

The many possible problems associated with creating a general methodology for multisensor integration are methods used for the modeling of error or uncertainty. The error which is in sensory information is usually caused by the random noise process and its modeling. Here the problem of noise will usually occur in the system. This noise is to be removed by the best estimation process .For which kalman filter has been selected When in the kalman filter noise exceeds the noise level, uncertainty occurs in the estimation. As a result of this the system will go in unstable mode. To reduce the instability of the system fuzzy logic technique has been proposed to be used. The combine effort of the fuzzy kalman filter will be observed for noise, stability, increase in the noise level and uncertainty.

\section{DATA FUSION}

Data fusion is the process of combing information from variety of different sources to provide a robust and complete description of an environment or process of interest. Data fusion enjoys special significance in any application where large amounts of data has to be combined, fused and distilled to obtain information of appropriate quality and integrity on which decisions can be based. The applications of data fusion include many military systems, civilian surveillance and monitoring tasks, process control and information systems. 
Data fusion methods are particularly important in the drive towards autonomous systems in all these applications. In principle, automated data fusion processes allow essential measurements and information to be combined to provide knowledge of sufficient richness and integrity that decisions may be formulated and executed autonomously.

Data fusion is often (somewhat arbitrarily) divided into a hierarchy of four processes.

- Levels 1 and 2 of this process are concerned with the formation of track, identity, or estimate information and the fusion of this information from several sources. Level 1 and 2 fusion is thus generally concerned with numerical information and numerical fusion methods (such as probability theory or Kalman filtering).

- Level 3 and 4 of the data fusion process is concerned with the extraction of "knowledge" or decisional information. Very often this includes qualitative reporting or secondary sources of information or knowledge from human operators or other sources. Level 3 and 4 fusion is thus concerned with the extraction of high-level knowledge (situation awareness for example) from low level fusion processes, the incorporation of human judgment and the formulation of decisions and actions.

This hierarchy is not, by any means, the only way of considering the general data fusion problem. It is perhaps appropriate for many military data fusion scenarios, but is singularly inappropriate for many autonomous systems or information fusion problems. The imposition of a "hierarchical" structure to the problem at the outset can also serve to mislead the study of distributed, de centralized and network-centric data fusion structures. Nevertheless, the separate identification of numerical problems (tracking, identification and estimation) from decisional and qualitative problems (situation awareness, qualitative reporting and threat assessment) is of practical value. These are concerned with the fusion of information from sensors and other sources to arrive at an estimate of location and identity of objects in an environment. It encompasses both the direct fusion of sensor information and the indirect fusion of estimates obtained from local fusion centers. The primary methods in level 1-2 fusion methods are probabilistic. These include multi target tracking, track-totrack fusion, and distributed data fusion methods. Level 3-4 data fusion problems are considered in less detail. These involve the modeling of qualitative information sources, the use of non-probabilistic methods in describing uncertainty and general decision making processes. Level 3-4 data fusion, obviously, builds on level 1-2 methods.

\section{CHALLENGES IN THE DATA FUSION}

Data fusion techniques combine data from multiple sensors and related information to achieve more specific inferences than could be achieved by using a single, independent sensor. Data fusion refers to the combination of data from multiple sensors (either of the same or different types), whereas information fusion refers to the combination of data and information from sensors, human reports, databases, etc.

The concept of multisensor data fusion is in practice from old times. As humans and animals evolved, they developed the ability to use multiple senses to help them survive. For example, assessing the quality of an edible substance may not be possible using only the sense of vision; the combination of sight, touch, smell, and taste make it far more effective. Similarly, when vision is limited by structures and vegetation, the sense of hearing can provide advanced warning of impending dangers. Thus, multisensory data fusion is naturally performed by animals and humans to assess more accurately the surrounding environment and to identify threats, thereby improving their chances of survival. Interestingly, recent applications of data fusion have combined data from an artificial nose and an artificial tongue using neural networks and fuzzy logic.

Although the data fusion is in use since long, the emergence of new sensors, advanced processing techniques, improved processing hardware, and wideband communications has made real-time fusion of data increasingly viable. Just as the advent of symbolic processing computers (e.g., the Symbolic computer and the Lambda machine) in the early 1970 s provided an impetus to artificial intelligence, the recent advances in computing and sensing have provided the capability to emulate, in hardware and software, the natural data fusion capabilities of humans and animals. Currently, data fusion systems are used extensively for target tracking, automated identification of targets, and limited automated reasoning applications. Data fusion technology has rapidly advanced from a loose collection of related techniques to an emerging true engineering discipline with standardized terminology, collection of robust mathematical techniques, and established system design principles.

A key challenge in multisensor data fusion is co-registration. This problem requires the alignment of two or more sensor input so that the fused output will not give more changes. This co registration problem is 
exacerbated by the fact that sensors are nonlinear and they perform a complex transformation between the sensed inputs. The monitoring of complex mechanical equipment such as turbo machinery, helicopter gear trains, or industrial manufacturing equipment are few other examples of nonlinear input.

For a drive train application, sensor data can be obtained from accelerometers, temperature gauges, oil debris monitors, acoustic sensors, and infrared measurements. An online condition-monitoring system would seek to combine these observations to identify precursors to failure such as abnormal gear wear, shaft misalignment, or bearing failure. The use of such condition-based monitoring is expected to reduce maintenance costs and improve safety and reliability.

\section{COMPARISON OF WORK CARRIED OUT BY RESEARCHERS}

Table 1: Comparison of literatures

\begin{tabular}{|c|c|c|c|}
\hline $\begin{array}{l}\text { SR } \\
\text { NO }\end{array}$ & AUTHORS & DESCRIPTION OF WORK & SHORT COMINGS \\
\hline 1 & Ren C Leo & $\begin{array}{l}\text { Presented the survey of Multisensor system. } \\
\text { Pointed out following errors as, } \\
\text { - Integration and fusion process error } \\
\text { - Sensory information error } \\
\text { - System information error }\end{array}$ & $\begin{array}{l}\text { Lower accuracy and } \\
\text { phase delay }\end{array}$ \\
\hline 2 & Lang Hong & $\begin{array}{l}\text { Proposed an algorithm for adaptive data fusion } \\
\text { which can be employed in uncertain sensed } \\
\text { environment. Considered unknown noise statistics } \\
\text { of the modeling error, measurement error and the } \\
\text { network uncertainties. Explained benefits of multi- } \\
\text { sensor fusion technology. }\end{array}$ & $\begin{array}{l}\text { Issues related to the noise } \\
\text { are not focused }\end{array}$ \\
\hline 3 & $\begin{array}{l}\text { J.Z. Sasiadek \& P. } \\
\text { Hartana }\end{array}$ & $\begin{array}{l}\text { Reported work on data fusion system for Mobile } \\
\text { robot navigation. Odometry and sonar signals are } \\
\text { fused using Extended Kalman Filter- (EKF) and } \\
\text { Adaptive Fuzzy Logic System (AFLS). }\end{array}$ & $\begin{array}{l}\text { Problem in gain adaption } \\
\text { for application }\end{array}$ \\
\hline 4 & $\begin{array}{ll}\text { Sumedh Puranik } & \& \\
\text { Dr. Thomas } & \text { C. } \\
\text { Jannett } & \end{array}$ & $\begin{array}{l}\text { Reported work on data fusion algorithms used for } \\
\text { multi-sensor tracking in the context of Deployable } \\
\text { Autonomous Distributed System (DADS). }\end{array}$ & $\begin{array}{l}\text { Uncertainty in estimating } \\
\text { the target position }\end{array}$ \\
\hline 5 & $\begin{array}{l}\text { D. P. Atherton \& } \\
\text { J. A. Bather }\end{array}$ & $\begin{array}{l}\text { The work described examines the accuracy of the } \\
\text { Bar-Shalom formula for computing the fused } \\
\text { estimate from two filters tracking a single target } \\
\text { with the exact minimum mean square estimator. It } \\
\text { was found that when the filter Q was taken to be } \\
0.1 \text { times that of the actual target noise the filter } \\
\text { with the best measurement accuracy did better than } \\
\text { was obtained by fusing }\end{array}$ & $\begin{array}{l}\text { Cascading of Kalman } \\
\text { filter for single target }\end{array}$ \\
\hline 6 & $\begin{array}{l}\text { K. } \\
\text { Rajaduraimanickam } \\
\& \\
\text { J. Shanmugam }\end{array}$ & $\begin{array}{l}\text { This work deals with a new approach based on } \\
\text { Kalman Filtering for navigation sensor data fusion } \\
\text { obtained from ADDR navigation system and GPS. } \\
\text { The modeling of ADDR and GPS dynamics has } \\
\text { been developed, simulated for its error sources and } \\
\text { position accuracies to determine the co-variance } \\
\text { matrix. }\end{array}$ & $\begin{array}{l}\text { Data fusion } \\
\text { Unmanned vehicle }\end{array}$ \\
\hline 7 & $\begin{array}{l}\text { AI-Dhaher } \quad \& \quad \text { D. } \\
\text { Mackesy }\end{array}$ & $\begin{array}{l}\text { Obtained fused measured data that represent the } \\
\text { measured parameter as accurate as possible. The } \\
\text { architecture is based on the use of adaptive Kalman } \\
\text { filter formed by combining Kalman filter and fuzzy } \\
\text { logic techniques. }\end{array}$ & $\begin{array}{l}\text { Filter Divergence at the } \\
\text { time of tuning }\end{array}$ \\
\hline
\end{tabular}




\begin{tabular}{|c|c|c|c|}
\hline 8 & $\begin{array}{l}\text { Jamshaid Ali \& Fang } \\
\text { Jiancheng }\end{array}$ & $\begin{array}{l}\text { Developed a decentralized unscented Kalman Filter } \\
\text { (UKF) in federated configuration for multisensor } \\
\text { navigation data fusion. The UKF is a nonlinear, } \\
\text { distribution approximation method that uses a finite } \\
\text { number of points to propagate the state's probability } \\
\text { distribution through the system's nonlinear } \\
\text { dynamics. }\end{array}$ & $\begin{array}{l}\text { Failure in the sensors will } \\
\text { not be addressed }\end{array}$ \\
\hline 9 & $\begin{array}{l}\text { David Macii, Andrea } \\
\text { Boni, Mariolino De } \\
\text { Cecco, and Dario } \\
\text { Petri }\end{array}$ & $\begin{array}{l}\text { They have presented the basic overview of data } \\
\text { fusion terminology, models, and algorithms with } \\
\text { the help of some examples related to next } \\
\text { generation car safety and driver assistance systems. } \\
\text { Applications:- for military applications in ocean } \\
\text { surveillance, air-to air and surface-to-air defense, or } \\
\text { battlefield intelligence. Describes some data fusion } \\
\text { models and some applications to next-generation } \\
\text { car safety and driver assistance systems etc }\end{array}$ & $\begin{array}{l}\text { Basic overview of data } \\
\text { fusion and algorithms for } \\
\text { military application }\end{array}$ \\
\hline 10 & $\begin{array}{l}\text { Suyi Liu Shuqing } \\
\text { Wang }\end{array}$ & $\begin{array}{l}\text { Presented the modified multi resolution analysis } \\
\text { method and the wavelet domain median filter. It is } \\
\text { found that wavelet transformation combining with } \\
\text { Kalman filter is the most used method in the } \\
\text { research of multisensory data fusion algorithm. }\end{array}$ & $\begin{array}{l}\text { Low resolution in high } \\
\text { frequency band }\end{array}$ \\
\hline 11 & $\begin{array}{l}\text { P. J. Escamilla- } \\
\text { Ambrosio and N. } \\
\text { Mort }\end{array}$ & $\begin{array}{l}\text { Multi-Sensor Data Fusion (MSDF) architecture } \\
\text { integrating Kalman filtering and fuzzy logic } \\
\text { techniques has been explored. The objective of the } \\
\text { hybrid MSDF architecture is to obtain fused } \\
\text { measurement data that determines the parameter } \\
\text { being measured as precisely as possible }\end{array}$ & $\begin{array}{l}\text { Problem of uncorrelated } \\
\text { noise }\end{array}$ \\
\hline 12 & $\begin{array}{l}\text { P. J. Escamilla- } \\
\text { Ambrosio and N. } \\
\text { Mort }\end{array}$ & $\begin{array}{l}\text { Suggested a novel Multi-Sensor Data Fusion } \\
\text { (MSDF) architecture The effectiveness and } \\
\text { accuracy of this approach is demonstrated in a } \\
\text { simulated example. }\end{array}$ & $\begin{array}{l}\text { Trial \& error scheme of } \\
\text { fuzzy logic is } \\
\text { implemented }\end{array}$ \\
\hline
\end{tabular}

\section{CONCLUSION}

A key challenge in multisensor data fusion is co-registration. This problem requires the alignment of two or more sensor input so that the fused output will not very much. This co registration problem is exacerbated by the fact that sensors are nonlinear and they perform a complex transformation between the sensed inputs. The use of condition-based monitoring is expected to reduce maintenance costs and improve safety and reliability.

The following issues are observed in data fusion:

- There is no substitute for a good sensor.

- Downstream processing cannot absolve the sins of upstream processing.

- The fused answer may be worse than the best sensor.

- There are no magic algorithms.

- There will never be enough training data.

- It is difficult to quantify the value of data fusion.

- Fusion is not a static process.

\section{REFERENCES}

[1] J.Z. Sasiadek, P. Hartana, "Sensor Data Fusion Using Kalman Filter", Carleton University, Ottawa, Ontario, Canada, pp.19-25, 2000

[2] P. J. Escamilla-Ambrosio and N. Mortl, "A Hybrid Kalman Filter-Fuzzy Logic Architecture For Multisensor Data Fusion" 
International Symposium on Intelligent Control, Mexico City, Mexico, September 2001, pp.64-69 , 2001

[3] P.J.Escamilla-Ambrosio, N.Mort, "Multisensor Data Fusion Architecture Based on Adaptive Kalman Filters and Fuzzy Logic Performance Assessment", Sheffield, UK, ISIF, pp.1542-1549, 2002

[4] P.J.Escamilla-Ambrosio, N.Mort, “A Novel Design and Tuning Procedure for PID Type Fuzzy Logic Controllers”, IEEE Symposium Intelligent Systems, September 2002, pp. 36-41, 2002

[5] S.Puranik , T.C. Jannett, “ A Comparison of the Tracking Performance of Some Distributed Multi-Sensor Data Fusion Algorithms Based on Kalman Filter Methods" IEEE,pp. 455-459,2003

[6] P.J.Escamilla-Ambrosio, N.Mort, "Hybrid Kalman Filter-Fuzzy Logic Adaptive Multisensor Data Fusion Architectures", IEEE Conference on Decision and Control, Hawaii USA,Dec 2003, pp. 5215-5220, 2003

[7] D. P. Atherton and J. A. Bather, "Data Fusion for Several Kalman Filters Tracking a Single Target" , Brighton, UK,University of Sussex, pp.63-69

[8] A. H. G. AI-Dhaher and D. Mackesy, "Multi-Sensor Data Fusion Architecture", University of Ottawa, IEEE , pp. 159-164,2004

[9] D.P. Atherton, J.A. Bather and A.J. Briggs "Data fusion for several Kalman filters tracking a single target ", IEEE Proc.-Radar Sonar Navig., Vol. 152, pp. 372-376, October 2005

[10] K. Rajaduraimanickam, J.Shanmugam “Addr-Gps Data Fusion Using Kalman Filter Algorithm”, IEEE Digital Avionics Systems Conference, October 30, 2005

[11] J.Ali and F.Jiancheng "Multisensor Data Synthesis using Federated Form of Unscented Kalman Filtering", University of Aeronautics and Astronautics,Beijing,China, pp.524-529, 2005

[12] Duncan Smith and Sameer Singh “Approaches to Multisensor Data Fusion in Target Tracking: A Survey", IEEE Transactions On Knowledge And Data Engineering, Vol. 18, December 2006,pp. 1696-1710, 2006

[13] J. G. Herrero, J. R..C Corredera, J.R B.Portas, "On-Line Multi-Sensor Registration for Data Fusion on Airport Surface", IEEE Transactions on Aerospace and Electronic Systems, Vol. 43,January 2007,pp. 356-370, 2007

[14] D. Macii, A. Boni, M. De Cecco, and D. Petri, "Tutorial 14: Multisensor Data Fusion”, IEEE Instrumentation \& Measurement Magazine, June 2008, pp. 24-33, 2008

[15] S. Liu ,S. Wang, "Modified Wavelet Transformation Algorithms and Its Application in Multi-Sensor Data Fusion", IEEE Intelligent Control and Automation, Chongqing, China, June 25 - 27, 2008, pp. 4986-4989, 2008

[16] Felix Opitz, "Multisensor Data Fusion in Network-Centric Operations", IEEE on Defence and Communications Systems,2008

[17] E. E. EI Madbouly, A. E. Abdalla, Gh. M. EI Banby, "Fuzzy Adaptive Kalman Filter for Multi-Sensor System", IEEE, pp. 141-145, 2009

[18] X. Wang, D.M. Sicki, R. Ellem, F. Fletcher, "Efficient and Enhanced Multi-Target Tracking with Doppler Measurements" IEEE Transactions on Aerospace and Electronic Systems Vol. 45, October 2009,pp. 1400-1417, 2009

[19] L. Jargani, M. Shahbazian, K. Salahshoor, V. Fathabadi, "State Estimation of Nonlinear Systems Using Novel Adaptive Unscented Kalman Filter, IEEE International Conference on Emerging Technologies, pp 124-129, 2009

[20] C. Zhang, H. Wang "Decentralized Multi-Sensor Data Fusion Algorithm Using Information Filter", IEEE International Conference on Measuring Technology and Mechatronics Automation, pp. 890-892, 2010 